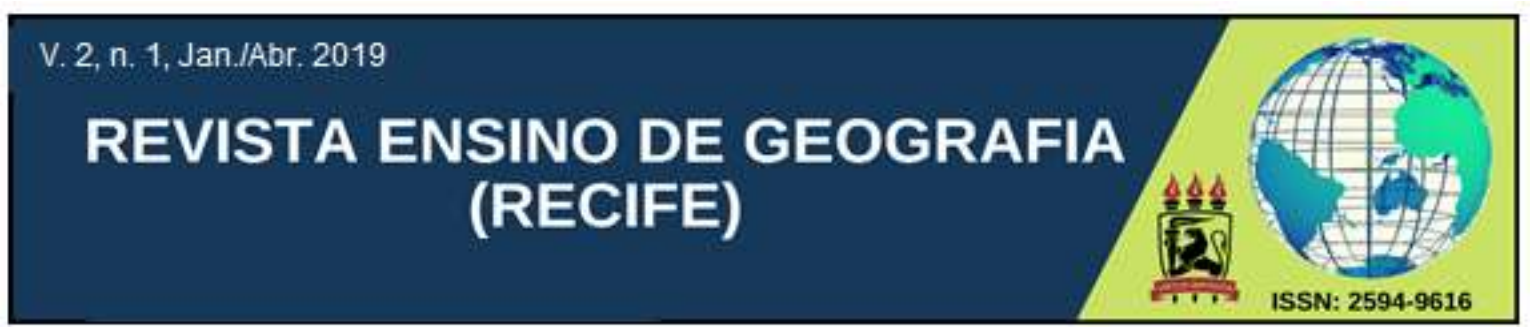

\title{
EDUCAÇÃO PELA PESQUISA E A APRENDIZAGEM DA GEOGRAFIA ESCOLAR
}

\author{
Douglas Vinícius Stumm \\ Acadêmico do curso de Licenciatura em Geografia do Centro Universitário Uninter \\ douglasstumm@gmail.com \\ ORCID iD: https://orcid.org/0000-0001-8008-6833
}

Artigo recebido em 15/01/2019 e aceito em 22/03/2019

\begin{abstract}
RESUMO: A aprendizagem escolar dos discentes deixa muito a desejar. Os dados obtidos pelas avaliações externas comprovam tal situação. Tal problema tem causas multifatoriais, porém a principal delas vem a ser o modelo didático-metodológico instrucionista baseado unicamente nas aulas, as quais possuem um rito préestabelecido e, normalmente, são seguidas à risca pelos docentes. Todas as disciplinas escolares são afetadas por esta baixa aprendizagem, inclusive a disciplina de geografia que não vem cumprindo suas funções na escolarização, bem como tem se tornado inócua e insossa devido a forma como é trabalhada. Dessa forma, por meio de levantamento bibliográfico, busca-se expor uma maneira mais adequada de trabalhar com estes conhecimentos, especialmente na construção e reconstrução de habilidades e competências, as quais se fazem necessárias na atualidade perante o mundo globalizado. A partir disso, defende-se que o modelo de educação pela pesquisa proposto pelo professor Pedro Demo seria o mais adequado, isto é, cumpre o papel de propiciar oportunidades de aprendizagem significativa aos discentes, outorgando ao professor o papel de mediador deste processo. Ademais, tal modelo didático-metodológico tem como eixo central o aprender a aprender e não o trabalho pormenorizado com uma enorme carga de conteúdos, o que é bastante adequado.
\end{abstract}

Palavras-chave: Aprendizagem. Geografia escolar. Educação pela pesquisa.

\section{EDUCATION THROUGH RESEARCH AND LEARNING OF SCHOOL GEOGRAPHY}

\begin{abstract}
The students' school learning leaves much to be desired. The data obtained by the external evaluations prove this situation. This problem has multifactorial causes, but the main one is the instructional didactic-methodological model based solely on the classes, which have a pre-established rite and are usually followed strictly by the teachers. All school subjects are affected by this low learning, including the discipline of geography that has not fulfilled its functions in schooling, as well as has become innocuous and unsound due to the way it is worked. In this way, through a bibliographical survey, we seek to expose a more adequate way of working with this knowledge, especially in the construction of the reconstruction of skills and competences, which are necessary today in the globalized world. From this, it is argued that the research education model proposed by teacher Pedro Demo would be the most adequate, that is, it fulfills the role of providing significant learning opportunities to the students, granting the teacher the role of mediator of this process. In addition, such didactic-methodological model has as central axis the learning to learn and not the detailed work with a great load of contents, which is quite adequate.
\end{abstract}

Keywords: Learning. School geography. Education through research. 


\section{INTRODUÇÃO}

$\mathrm{Na}$ atualidade, muito se discute em torno do papel das disciplinas na escolarização dos alunos. Nesse debate são assumidas posições diversas e divergentes. Enquanto alguns defendem que as disciplinas têm uma importância inequívoca no processo de escolarização, outros afirmam que sua importância não é tão grande, cabendo, por vezes, uma integração destas em áreas do conhecimento sem qualquer prejuízo aos discentes e a seu processo de aprendizagem (CAVALCANTE, 2018; KRAUSZ, 2011; KRUSE \& PALHARES, 2017).

Concatenado a este debate, vem a questão do papel dos diferentes conteúdos aos quais tais campos disciplinares dizem respeito, enquanto atividade de trabalho consuetudinária. Constantemente, os docentes manifestam uma grande preocupação em "vencer" os conteúdos propostos para tal disciplina em determinado ano letivo. Contudo, conforme Demo (2009, p. 43), "passar por cima de raciocínios sequenciais, que se implicam mutuamente, significa tapar os vazios por meio de memorizações mecânicas", o que prejudica enormemente a aprendizagem significativa dos discentes.

$\mathrm{Na}$ tentativa de atenuar esta situação, cabe, inicialmente, uma reflexão quanto a origem deste problema. Estaria a causa destes baixos índices de aprendizagem no baixo interesse do aluno? Na má formação do professor? Na ausência de material didático e de apoio ao trabalho docente? Ou, ainda, estaria ela no modelo metodológico e didático atual? Ao nosso ver, por mais que o problema tenha múltiplas origens, dentre elas algumas supracitadas, a principal causa seria o modelo didático-metodológico presente atualmente em nossas escolas, sendo necessário, conforme Papert (1994, apud DEMO, 2009, p. 44) "refazer a didática [...], ou seja: cuidar que não se restrinjam a mero ensino (repasse instrucional), alcançando o saber pensar e o aprender a aprender".

Contudo, antes de adentrar esta seara, a qual está abarrotada de experiências supérfluas e descontextualizadas, que somente fazem uso de nomenclaturas diversas e "inovadoras", tendo por exemplo as chamadas metodologias ativas que "mais facilmente encobrem truques bisonhos para salvar a aula insuportável e inútil do que apresentam propostas que se comprometem com a autoria do estudante" (DEMO, 2018, p. 15) façamos uma análise necessária da visão conteudista que predomina na educação brasileira.

Neste contexto, temos como objetivo problematizar o modelo didático-metodológico utilizado atualmente na educação escolar e suas implicações no processo de ensino e aprendizagem da Geografia, além de propor um modelo mais adequado de aprendizagem, 
tendo como base a proposta de educação pela pesquisa do professor Pedro Demo, analisando suas implicações no trabalho com a disciplina de Geografia. A discussão desta temática se faz necessária pois, mesmo sendo lugar comum a necessidade urgente de mudanças no modelo instrucionista, as iniciativas apresentadas e adotadas até o presente momento tiveram pouco efeito qualitativo, prevalecendo uma aprendizagem inadequada. Para executar a nossa proposta de análise da temática da aprendizagem escolar e sua relação com a didática, dando ênfase à disciplina de Geografia, iremos proceder um levantamento bibliográfico sistemático de obras e autores com os quais visamos obter alguns direcionamentos para a resolução do problema da pesquisa, além de realizar pesquisas em sites da internet que tratem sobre o assunto.

\section{A APRENDIZAGEM ESCOLAR NA ATUALIDADE: O PROBLEMA DA DIDÁTICA}

Ao analisarmos o trabalho de qualquer docente em sala de aula, por diversas vezes, vemos um ritual que é seguido de forma sistemática por quase todos os professores, qual seja o tripé conteúdo, exercícios e prova. Ademais, normalmente esta tem notadamente caráter objetivo, mostrando que "o ensino tradicional permanece predominante na prática da disciplina escolar, pois se mantêm a transmissão e repassagem de dados formulados por meio da descrição e memorização [...]" (LIRA, 2014, p. 299-300). Indo além, cabe ressaltar que os conteúdos a serem trabalhados, muitas vezes, são organizados por sujeitos estranhos ao ambiente escolar, o que já sinaliza uma lacuna importante neste processo, isto é, os professores não constroem o seu próprio projeto de trabalho ou plano de estudos, seguindo prescrições dos livros didáticos.

Além disso, os mesmos são trabalhados de forma extremamente pormenorizada, isto é, com um detalhismo preciosista que beira o ridículo. Assim, os alunos recebem uma carga enorme de informações que, em grande parte das vezes, estão desatualizadas ou são, até mesmo, incorretas, na tentativa do professor de ensinar estas ao corpo discente pelo qual se acha responsável, pautados em uma perspectiva de aquisição e acumulação de conhecimentos. Vale ressaltar que “aprendizagem e conhecimento não se 'adquirem' (nem estão à venda), mas se elaboram mentalmente de maneira autoral, por condição evolucionária” (DEMO, 2018, p. 64). Em lugar de um verdadeiro aprendizado, verifica-se um cenário desalentador de tédio, indisciplina e ausência de aprendizado. 
Indo além, cabe-nos questionar a validade destes conteúdos de um ponto de vista pragmático. Os conteúdos que "ensinamos" nas diversas disciplinas presentes na escola, quando não transpostos didaticamente para a realidade em que o aluno está inserido, em alguns casos, não têm qualquer utilidade para estes do seu ponto de vista, pois "o distanciamento que se coloca entre o conteúdo e a realidade de suas vidas" (PEZZINI; SZYMANSKI, 2008, n.p). Quanto aos exercícios, cabe ressaltar que não são de todo inadequados a priori, mas os docentes fazem com que estes o sejam pelo modo como são aplicados em sala de aula. Para exemplificar tal situação, vamos citar como o exemplo o caso da Hidrogeografia.

Para iniciar, o docente apresenta uma imagem de uma bacia hidrográfica na qual está presente a nomenclatura específica das diferentes partes que a compõem, por exemplo, margens, afluentes, nascente, foz, jusante, montante, enfim, as nomenclaturas oficiais e convencionadas para tal recorte espacial das bacias hidrográficas. Estes nomes são repetidos algumas vezes pelo docente para, na sequência, copiá-los no caderno de maneira mecânica e sem qualquer tipo de reflexão. Agora, quanto aos exercícios, o mais grave surge quando estes são compostos de desenhos e formas muito similares onde o aluno somente precisa olhar em uma imagem para copiar para a outra.

Este procedimento de repetição pouco ou nada contribui para o aprendizado do aluno, visto que "tudo tende a reduzir-se a práticas instrucionistas deslavadas, no fundo, imbecilizantes, porque evitam a formação do sujeito que sabe pensar e aprender" (DEMO, 2004, p. 21). A situação supracitada é bem ilustrada pela seguinte anedota, a qual é bastante conhecida: A professora de português está ensinando algumas palavras aos seus alunos, sendo uma destas a palavra 'coube'. No entanto, um dos alunos não está conseguindo aprender e utiliza no lugar daquela, a palavra 'cabeu'. No intuito de ensinar a ele a palavra da forma correta, ordena que preencha totalmente uma folha de caderno, escrevendo a palavra de forma correta repetidas vezes. Após um tempo, ele traz a folha para a professora, que verifica que um pequeno espaço no final da folha ficou em branco e questiona o discente sobre qual o motivo daquele espaço. Eis que ele responde que não 'cabeu'.

Esta anedota é muito antiga, porém representa de maneira extremamente adequada o modelo instrucionista que está em voga nas escolas, ocasionando os índices pífios de aprendizagem que estão sendo verificados, a partir de ações do rito pedagógico que estão defasados e não favorecem a educação. Neste ínterim, onde está o aprendizado? 
Em nenhum momento houve qualquer tipo de inferência, participação e produção por parte dos alunos, isto é, eles não se tornaram autores da própria aprendizagem. Dando continuidade ao ritual, o docente, após a repetência de algumas "baterias" de exercícios marca o dia da prova. Neste momento, verifica-se uma situação que é bastante comum, qual seja o estudo por parte dos alunos "preocupando-se apenas em revisar estas aulas no dia da prova, visando apenas ser aprovado nas disciplinas" (OLIVEIRA. et. al., 2007, p. 1). Mas seria este um estudo que realmente conduz a um aprendizado satisfatório? Não é muito difícil responder a este questionamento, bastando observar qualquer sala de aula do ensino regular, seja esta de caráter público ou privado.

Instaura-se, assim, um ambiente de tensão muito grande e os alunos buscam simplesmente decorar os conteúdos até então trabalhados naquela determinada disciplina para reproduzi-los na avaliação. Esta avaliação, na imensa maioria das vezes, é composta de questões objetivas, as quais exigem pouca ou nenhuma reflexão, bastando que o aluno tenha decorado algumas coisas ou tenha uma boa dose de sorte para ser aprovado, já que "pode ser respondida ao acaso ou de memória, e sua análise não permite constatar quanto o aluno adquiriu de conhecimento" (BOTH, 2007, p. 90).

É possível notar que este modelo de aula e de ensino instrucionista, pressupõe a acumulação de conteúdos na memória dos discentes, o que é um grande erro.

Conforme Pedro Demo (2015, n.p.):

Grandes teorizações, como construtivismo, sociointeracionismo, maiêutica, autopoiese, contribuições da neurociência em especial, mesmo sendo todas incompletas naturalmente, sugerem que aprender é dinâmica de dentro, de estilo autoral, contando com pressões externas também, mas secundárias.

Isso mostra que é urgente a necessidade de mudar o modo com os docentes estão trabalhando com os seus alunos. Na área da geografia não é diferente. De acordo com Castellar (2005, p. 48),

Em relação ao ensino de geografia, penso que se deve superar as aprendizagens repetitivas e arbitrárias e passar a adotar outras práticas de ensino, investindo nas habilidades: análises, interpretações e aplicações em situações práticas; por isso, os currículos tradicionais ainda têm muito que mudar.

Mais do que somente uma mudança curricular, cabe aos docentes uma mudança paradigmática deixando de lado o conteudismo e passar a construir com seus alunos competências e habilidades que realmente façam a diferença para estes e lhes sejam úteis em 
sua vida. Cabe ressaltar que, a partir disso, não defendemos que os discentes devem inventar a roda a cada nova atividade de aprendizagem. Devem, sim, de forma autopoiética reconstruir o conhecimento de forma a compreendê-lo de maneira que faça sentido à sua existência e às suas relações no mundo. Nesse sentido, a aprendizagem leva a criar novas relações, ou seja, interligando conhecimentos até então desorganizados, que haviam sido repassados, mas não aprendidos.

Em suma, foi possível perceber que se enfatizou enormemente a questão do ensino, sendo que o professor se pauta neste "rito eclesiástico" que lhe foi ensinado na graduação de forma mecânica e sem muita reflexão. De acordo com Demo (2004, p. 36-37) "o problema crucial está em que a aula, como regra, não é fruto do saber pensar, mas da tendência reprodutiva". Ainda, algumas vezes, para dar um ar de professor moderno, este passa a utilizar algumas ferramentas tecnológicas neste processo, como apresentações de slides, computadores, jogos, enfim, adiáforos que nem sempre colaboram para a melhoria do processo de aprendizado.

Nesse sentido, cabe ressaltar que utilizar recursos tecnológicos sem repensar a metodologia é seguir reproduzindo modelos de ensinos pautados no modo expositivo, sem efetiva participação dos alunos. Os slides, por exemplo, podem ser meramente lidos pelo docente ou copiados pelos alunos sem qualquer debate ou produção. Os computadores podem servir meramente como elementos distratores ou "prêmios" para os alunos que terminam suas atividades na sala de aula, bem como os jogos que podem ser passatempos para sala de aula quando utilizados fora de qualquer contexto pedagógico.

\subsection{OS ALUNOS APRENDEM ALGUMA COISA NA ESCOLA?}

Quando se fala de aprendizagem sempre há uma grande celeuma, isto é, devido à existência de diversas concepções do que significa realmente aprender, não há consenso por parte de todos os teóricos. Contudo, levando em conta a concepção de aprendizagem acima referida como processo autoral, autopoietico e construtivo, podemos afirmar que esta pouco vem ocorrendo pois, conforme Pedro Demo (2004, p. 44), grande parte dos alunos "jamais estudou de verdade ou aprendeu a estudar, nunca pesquisou, não tem habilidade para construir texto ou projeto próprio, não tem ideia de atividades como argumentar, fundamentar, questionar, não sabe pensar”. 
Os exemplos acima referidos, tais como argumentação, questionamento, entre outros, são elementos básicos que denotam a ocorrência de uma efetiva aprendizagem, já que demandam uma conjuntura bastante significativa de habilidades e competências que poderiam ser aprendidas no ambiente educativo, mas não o são pela perversidade do modelo instrucionista atual. Neste interregno, entre o início dos trabalhos com algum conteúdo e a avaliação do aprendizado deste, muito se ensina, porém pouco se aprende.

Os dados obtidos pelas avaliações externas como o PISA e por índices como o IDEB mostram isso, pois na série histórica iniciada a partir dos anos de 1990 os números têm piorado cada vez mais, especialmente em Matemática e em Língua portuguesa (DEMO, 2018).

Para exemplificar tal situação, vamos apresentar uma breve análise dos dados obtidos no IDEB nos últimos anos de forma geral, ou seja, sem pormenorizações ou exposição de dados muito específicos, conforme Quadro 1 abaixo relacionado:

\begin{tabular}{|c|c|c|c|c|c|l|l|}
\hline \multicolumn{7}{|c|}{ Anos Finais do Ensino Fundamental } \\
\hline \multirow{3}{*}{ Total } & 3,5 & 3,8 & 4,0 & 4,1 & 4,2 & 4,5 & 4,7 \\
\cline { 2 - 8 } & 2005 & 2007 & 2009 & 2011 & 2013 & 2015 & 2017 \\
\hline
\end{tabular}

No quadro acima é possível observar que, do ponto de vista dessa avaliação, houveram evoluções no que tange ao aprendizado dos alunos, contudo os dados são muito desanimadores pois os índices de aprendizagem continuam numericamente muito baixos e não estão evoluindo da maneira que deveriam, o que é ilustrado pela grande quantidade de células em branco no quadro, o que diz respeito aos períodos em que a meta do IDEB não foi atingida. A pior situação, no entanto, é percebida no ensino médio que é "mais nitidamente conteudista, que mais prega transmissão curricular crua, totalmente voltada para o ensino e instrução" (DEMO, 2018, p. 9), conforme podemos ver no Quadro 2.

\begin{tabular}{|c|c|c|c|c|c|l|l|}
\hline \multicolumn{7}{|c|}{ Ensino Médio } \\
\hline & \multicolumn{7}{|c|}{ IDEB OBSERVADO } \\
\cline { 2 - 8 } & 2005 & 2007 & 2009 & 2011 & 2013 & 2015 & 2017 \\
\hline Total & 3,4 & 3,5 & 3,6 & 3,7 & 3,7 & 3,7 & 3,8 \\
\hline
\end{tabular}

Fonte: INEP 
É possível observar que, ao contrário dos anos finais do ensino fundamental que ainda tiveram alguma evolução positiva, no ensino médio o cenário é de estagnação. Assim, "como todas as aulas foram dadas, todas as provas aplicadas, todos os conteúdos transmitidos, essas atividades de ensino soam sugestivamente inúteis" (DEMO, 2018, p. 10). No entanto, os órgãos dirigentes da educação brasileira como o Ministério da Educação (MEC) e as secretarias da educação parecem não querer ver tal situação, já que adotam atitudes totalmente contraproducentes, e isto fazem apoiados pelos docentes.

A partir destes dados, podemos afirmar que, é feito, por vezes, um trabalho didático inadequado e que não é condizente com a efetiva aprendizagem dos estudantes, precipuamente no que tange à escolarização básica. De acordo com Lück (1994, apud AUGUSTO et. al., 2004, p. 279),

\footnotetext{
Quando o saber é compartimentado em disciplinas, pode levar a conhecimentos bastante específicos focalizados em uma só área. Essa compartimentalização está presente na escola por meio das disciplinas específicas, e, entre as temáticas da sala de aula e a realidade vivida pelos estudantes, acaba por gerar a alienação e a irresponsabilidade dos aprendizes, que não se sentem parte dos fenômenos e, portanto, capazes de mudá-los.
}

E qual seria a principal ação corretiva adotada? Mais tempo de aula nas escolas, maior carga horária das disciplinas e, consequentemente, mais conteúdo. Mas será que isso funciona? Os dados mostram que não. Emblemático é o exemplo do IDEB no ano de 1999 quando se verificou uma queda abrupta nos resultados obtidos pelos alunos como, até hoje, não mais se viu. O que teria propiciado tal cenário? Demo (2018) defende que, já que não houve nenhum choque nas políticas de acesso à educação, nenhuma turbulência política mais incisiva que pudesse afetar estes resultados, somente haveria uma explicação, qual seja o aumento no número de dias letivos para a taxa atual que é de duzentos (200).

Já naquele contexto, tal atitude não teve nenhum efeito positivo, e hoje se incorre no mesmo erro ao defender a escola de tempo integral neste modelo instrucionista. Conforme Demo (2009, p. 170),

Se mantivermos os níveis atuais de precariedade, aumentar os dias de aula não acrescentará nada, precisamente porque quase nada se aprenderá. Esta rota é equivocada. Não seria exagero aventar que, para aprender o pouco que se aprende na escola, bastaria um terço dos dias de aula, se fosse bem dada. O problema é que temos na cabeça a quimera de que a escola é aula, aprender é aula, estudar é aula. Se tirássemos a aula da escola, esta desapareceria... 
Quando, finalmente, abrimos os olhos para os índices de aprendizado horrorosos que temos hoje em dia em nosso sistema educacional, a primeira sugestão que se mostra como tábua de salvação é o aumento de carga horária das disciplinas, o que acarreta, de forma lógica, o aumento da carga de conteúdos para que os discentes absorvam, sendo esta absorção de forma literal como se os alunos fossem esponjas que não ficassem saturadas em nenhum momento, absorvendo qualquer substância líquida que fosse jogada sobre ela de forma indefinida.

Neste momento, é importante que estejamos cientes de que isso não irá funcionar, pois o foco central deste processo encontra-se deslocado do seu alvo que é o aprendizado dos alunos. Será que um aluno aprende nos ouvindo, isto é, ouvindo nossas aulas chatas e enfadonhas? Já sabemos que não, mas a solução que encontramos é aumentar a carga horária de aulas das nossas disciplinas!

Além de ser bastante contraditório, representa um desperdício de dinheiro público, pois trata-se de uma política pública que preza o ensino, mas não aprendizado. Os dados do PISA não são muito diferentes, já que mostram uma queda significativa nos resultados obtidos pelos estudantes brasileiros $(\mathrm{G} 1,2016)$.

Os dados do PISA e do IDEB mostram que a educação está parada no tempo ou regredindo em alguns casos, conforme vimos acima. Cabe mencionar que não estamos advogando o fim da escola ou do professor, mas propondo que esta relação educativa seja reconstruída de forma a preconizar o aprendizado e isto se poderá fazer de uma maneira bastante simples, conforme propõe o professor Pedro Demo, isto é, tornando o aluno um autor do seu próprio conhecimento. Assim, sua proposta advoga que devemos deixar de lado este preciosismo das disciplinas e focar no desenvolvimento do eixo central do saber escolar, enfatizando, conforme supracitado, a autoria dos discentes (DEMO 2018, 2015, 2009, 2004).

Contudo, pouco se faz nesse sentido, e não por culpa única e exclusivamente do professor, mas também da formação que este recebe, baseada neste tripé conteúdo, exercícios e avaliação e que ele simplesmente reproduz, já que é isso que o docente aprende na graduação que "só existem aula, prova e repasse" (DEMO, 2018, p. 14). O professor não aprende a aprender ao longo da graduação, não aprende a pesquisar, a redigir e sistematizar os resultados de suas observações e, logicamente, não faz isso com os seus alunos, o que gera os resultados que conhecemos hoje em dia, que são verdadeiras tragédias.

Em síntese, até aqui foi possível auferir dados terríveis de aprendizagem de forma geral, dados alimentados principalmente pela aprendizagem em português e matemática. E 
nas outras disciplinas? A situação está muito melhor? É possível “medir” isso de alguma maneira? Consideramos que sim, seja possível, mas antes é preciso contextualizar esta disciplina quanto à sua função na escolarização, isto é, definir qual o seu papel na escola e isto nos propomos a fazer com a Geografia.

\subsection{OS ALUNOS ESTÃO APRENDENDO GEOGRAFIA NA ESCOLA?}

O questionamento referente à função da geografia no ambiente escolar perpassa alguns pressupostos epistemológicos e históricos deste campo disciplinar. Cabe ressaltar que a resposta a tal questionamento nem sempre é clara, o que acarreta, por vezes, um trabalho inadequado para com os conhecimentos geográficos, formando assim "uma ideia que permanece em nós, mesmo depois de termos abandonado a escola: a da Geografia como ensino árido, classificatório e distante da nossa realidade" (KAERCHER, 1999 apud KAERCHER, 2014, p. 116).

É importante que façamos um trabalho de cunho reflexivo e prático de maneira constante para que consigamos, por meio de um trabalho efetivo e adequado para com os discentes, descontruir tal visão, já que a geografia é muito importante " para uma leitura mais dinâmica, interessante e curiosa do mundo" (KAERCHER, 2014, p. 18). Conforme Cavalcanti (2002) e Castellar e Vilhena (2011 apud BALISKI, 2016, p. 30) o objetivo principal da geografia escolar é o desenvolvimento do raciocínio espacial. Cavalcanti (2002 apud BALISKI, 2016, p. 30) afirma que:

[...] esse tipo de raciocínio é importante para a efetivação das práticas sociais variadas, pois estas, sejam as do nosso cotidiano, sejam as mais amplas (como as do Estado ou das grandes corporações empresariais), são também espaciais, pois ocorrem no espaço geográfico. É relevante acrescentar, ainda, que, em uma concepção dialética, ao mesmo tempo que as práticas sociais são influenciadas pelo espaço, elas também o influenciam e o transformam. Isso torna o conhecimento geográfico relevante para a vida cotidiana e para o próprio desenvolvimento da sociedade no decorrer do tempo.

Dessa maneira, considerando a citação é nítida e notória a importância da Geografia escolar, bem como de seu aprendizado adequado. Ademais, cumpre citar que a disciplina, a partir dessa função central de desenvolvimento do raciocínio espacial, tem papel preponderante enquanto conhecimento útil à desnaturalização de ideologias e como alternativa à alienação (PEREIRA, 2016). 
Tais características nos levam principalmente à construção da capacidade de expor seus pensamentos e suas ideias com coerência, fundamentando nossas posições sempre na autoridade do argumento, além de consolidar a capacidade de pensar, ou seja, de sermos minimamente cidadãos capazes de ser partícipes na sociedade de forma adequada. Todavia, não é isso que percebemos na sociedade atual, especialmente, nos jovens que estão concluindo seu processo de escolarização ao assumir posições e discursos sem nenhum tipo de embasamento sólido, ficando somente no senso comum, além de não ter nenhuma capacidade autoral, seja ela de cunho acadêmico ou de projeto de vida.

Conforme Pedro Demo (2018, p. 13):

\begin{abstract}
Bastaria lembrar que no Enem 2015, apenas 70 estudantes obtiveram nota máxima em redação - ninguém sabe redigir! No PISA 2015, cerca de 44\% dos estudantes brasileiros que participaram ficaram abaixo do último lugar (Brasil no PISA 2015, 2016). Segundo o INAF (Indicador Nacional de Alfabetismo Funcional), apenas 8\% dos brasileiros adultos seriam "proficientes" (digamos, "sabem pensar"!)
\end{abstract}

Tal situação denota que a geografia escolar não vem cumprindo seu papel, quer dizer, sendo o raciocínio espacial, juntamente com a desnaturalização de ideologias e alternativa à alienação, às funções da geografia escolar, um cenário como o citado acima, não denota de qualquer forma um aprendizado adequado. Além disso, de acordo com Carneiro (1993 apud BALISKI, 2016, p. 35) “o ensino de geografia na educação básica contribui para a formação de três dimensões do desenvolvimento humano: intelectual, atitudinal e psicomotora". Para exemplificar tais observações a autora cita as seguintes habilidades: observação, análise, comparação, síntese, avaliação, sensibilidade, conscientização e interpretação.

Resumindo, "pensar na importância e na influência do espaço, na fisicidade das coisas e na geograficidade da nossa existência é uma das grandes contribuições que a geografia pode dar" (KAERCHER, 2007, p. 16). De posse destes resultados e destas análises, é possível adotar alguma medida que altere tal situação para melhor? Em nossa opinião sim, e é isto que propomos em seguida.

\title{
3 UMA ALTERNATIVA À GEOGRAFIA ESCOLAR: PRESSUPOSTOS DIDÁTICO- METODOLÓGICOS
}

Inicialmente, cabe destacar qual a concepção de aprendizagem que consideramos neste trabalho para que seja possível alinhar a nossa proposta a este pressuposto. 
Ao nosso ver, afirmar que o conhecimento é assimilado pelo aluno é um grande erro prático e conceitual, o qual contribui enormemente para a situação desalentadora que se mostra na aprendizagem nos dias de hoje. Mais correto seria dizer que o conhecimento, na imensa maioria das vezes, é reconstruído e em algumas vezes é construído. Conforme Demo (2018, p. 63):

\begin{abstract}
Aprender é processo de autodesenvolvimento dos seres vivos em geral autopoietico, para Maturana (2001), acentuando o movimento autoral, de dentro para fora (DEMO 2002, 2015), por meio do qual nos reconstruímos pela vida afora movidos por fatores internos e externos.
\end{abstract}

Além disso, uma variável importante na reconstrução do conhecimento é o interesse. Para ilustrar tal afirmação, vejamos um caso prático. Em diversas situações estamos conversando com alguém e repentinamente nos "pegamos" com o pensamento no "mundo da lua" e não compreendemos nada do que a outra pessoa falou, por mais que estivéssemos suficientemente próximos a ela e não tivéssemos qualquer tipo de problema de audição ou de compreensão.

Assim, também, são alguns alunos em sala de aula, ao ouvirem o monólogo dos professores, isto é, talvez até estejam ouvindo, porém não estão escutando. Se as informações e o conhecimento fossem repassados de um sujeito ao outro por mero processo de assimilação bastaria ouvir, mas não é isso que acontece. Para que consigamos reconstruir um conhecimento ou compreender um conjunto de informações é necessária uma atitude propositiva por parte do sujeito e de atenção, já que somente dessa maneira iremos aprender de forma efetiva e significativa.

Portanto, faz-se necessária uma renovação didática e metodológica, já que com o modelo atual 'tem-se pela frente o aluno 'vítima de aula', bocejando ou irrequieto, desligado ou alvoroçado, que comparece obrigado à aula para engolir conteúdos que, em geral, sequer entende" (DEMO, 2018, p. 15). De acordo com Cavalcanti (2005, p. 67) o modelo adotado deve ser algum em que

[...] o aluno é o sujeito ativo de seu processo de formação e de desenvolvimento intelectual, afetivo e social; o professor tem o papel de mediador do processo de formação do aluno; a mediação própria do trabalho do professor é a de favorecer/propiciar a interação (encontro/confronto) entre o sujeito (aluno) e o seu objeto de conhecimento (conteúdo escolar). Nessa mediação o saber do aluno é uma dimensão importante do seu processo de conhecimento (processo de ensinoaprendizagem). 
Indo além, cabe mencionar que a aprendizagem, conforme supracitado, somente ocorre por meio da mediação, a qual pressupõe em ambiente escolar a existência da linguagem, a qual é utilizada na interação entre aluno e professor, não de maneira instrucionista, mas sim dialógica. Contudo, nos moldes atuais de aula pautada unicamente nos monólogos ou nas conversas descabidas em sem fundamentos, tal mediação não ocorre, fazendo com que a linguagem seja usada como meio de instrução, que significa, de acordo com a etimologia do termo, o processo de empilhar ou amontoar algo em alguém.

A mediação é um processo de extrema importância neste contexto da educação, especialmente quando se advoga a necessidade de um novo modelo didático-metodológico, pois sem mediação não há como ocorrer o aprendizado. Assim, conforme Martins e Moser (2012, p. 10) "quando o cérebro humano aprende um conceito, usa a mediação das palavras ou a própria linguagem". Dessarte, é importante ter em mente que, com o modelo instrucionista, não há a ocorrência efetiva e profícua da mediação já que não há uma relação adequada entre o docente e o discente e o aprendizado, já que se manifesta a ocorrência de um simples monólogo por parte do docente, o qual o aluno por vezes não consegue compreender, perdendo a mediação a sua efetividade.

Convém, contudo, ressaltar que, conforme Wertsch (1998 apud MARTINS; MOSER, 2012, p. 11),

Os meios ou ferramentas que constituem a mediação não produzem o significado nem a aprendizagem, que é algo próprio da ação de cada indivíduo, porque uma ferramenta ou meio apenas possui uma ação na medida em que os indivíduos os usam.

Com isso, podemos perceber que urge adotarmos um novo modelo de aprendizado na educação, onde a mediação realmente ocorra e o aluno seja o sujeito mais importante deste processo. Dessa maneira, cabe-nos encontrar uma didática que se adapte ao nosso ambiente educacional em concordância com os pressupostos citados acima e, para tal, podemos observar as experiências de outros países que normalmente ocupam as primeiras posições nos rankings internacionais. Dentro de todas estas proposições, temos um ponto em comum, qual seja a existência de um modelo de educação pela pesquisa, e não um modelo instrucionista.

Neste modelo não são trabalhados 40 ou 50 temas diferentes com assuntos que, por vezes, são completamente estranhos aos alunos ou desconexos da realidade, mas sim, foca-se em alguns temas específicos e trabalha-se os mesmos de maneira exemplar. A adoção deste pressuposto didático-metodológico propicia melhores condições de aprendizagem de 
habilidades e competências essenciais à atuação cidadã na atualidade. Além disso, possibilita um trabalho com temas mais "interessantes" do ponto de vista dos alunos, já que, conforme Coll (1996 apud MORAES, 2005, p. 97), “aprender um conteúdo implica, do ponto de vista da psicologia cognitiva atual, atribuir-lhe um significado, construir uma representação ou modelo mental do mesmo".

Nos países mais desenvolvidos, as aulas estão sendo abolidas das escolas de educação básica e da graduação, sendo substituídas por uma proposta de projetos de pesquisa que trabalham com temas centrais e de interesse dos discentes, já que "a aprendizagem se faz melhor pela verticalização do conhecimento, [...] implicando leitura assídua, busca de dados e elementos, construção teórica, e, por fim, elaboração inteligente, seguida de apresentação" (DEMO, 2004, p. 91). Claro que deve haver, e há, um regramento muito claro deste trabalho para que a escola e a universidade não se tornem ambientes de libertinagem ou de passatempo, mas ambientes de aprendizado. E é justamente por isso que tais países ocupam as primeiras posições do ranking da educação mundial, pois focam no aprendizado do aluno e não no ensino do professor.

Cabe ressaltar que "dentro deste contexto, a aula vai continuar, mas recua para o fundo do cenário, como suporte. É incongruente ocupar o tempo todo com aula, porque evita-se estudar" (DEMO, 2004, p. 97). Ainda, “deveria ser regra a produção semanal de textos, dentro de processo permanente de reconstrução do conhecimento" (DEMO, 2004, p. 96). A partir disso, "muda radicalmente a avaliação, porque a prova se torna desnecessária" (DEMO, 2004, p. 96), possibilitando-se que esta cumpra sua função efetiva, que, conforme Ávila (1972 apud BOTH, 2007, p. 43) "é a ação de apreciar em seu justo valor um ser", e não somente com verificações objetivas que pouco dizem a respeito da evolução da aprendizagem do discente.

O ponto mais importante é que:

$\mathrm{O}$ professor precisa convencer o aluno de que deve estudar, pesquisar, elaborar. $\mathrm{O}$ aluno que aprende a estudar não depende de aula. Tem nisto enorme apoio para sua autonomia. Pobre do aluno que só funciona com aula, porque não vai além de copiar e reproduzir (DEMO, 2004, p. 99).

É importante mencionar que, conforme Demo (2009, p. 111) “educar pela pesquisa não é a última invenção, panaceia para nossos fracassos, modismo moderno", ou seja ela não é pura e simplesmente a salvação da lavoura, mas sim é uma das melhores, senão a melhor, alternativa ao processo de educação escolar, haja vista que propicia efetiva reconstrução do conhecimento, possibilitando aprendizagem significativa. Além disso, o discente assume um 
papel essencial neste processo de aprendizagem significativa, pois toda e qualquer proposta de aprendizagem não irá se consolidar caso ele não manifeste interesse na execução do mesmo.

A geografia escolar certamente se beneficiaria enormemente com a adoção deste método, deixando de ser vista como uma disciplina sem importância, ou ainda "coisa de professor", passando a ocupar o seu espaço enquanto campo do conhecimento com enorme importância, especialmente nos dias atuais, buscando deixar de lado o detalhismo e o preciosismo com que é trabalhada nas escolas.

Com isso, os conteúdos deixaram de ser atores centrais em nossas aulas, já que:

Nosso problema não são os conteúdos (sua falta ou seu excesso). Nem eles trazem, portanto, as soluções. [...] mais importante do que listar muitos conteúdos é entender o fio condutor que constrói as paisagens: os homens na sua luta pela sobrevivência (KAERCHER, 2003, p. 11)

A geografia escolar, nos moldes em que se encontra e que é trabalhada com os alunos, não cumpre todo seu papel, haja vista um a existência de um potencial que hoje se encontra adormecido, já que não cumpre suas funções em decorrência de não trabalhar com o seu objeto, que é o espaço geográfico, quer dizer, não ser trabalhada a sociedade e o mundo de forma articulada. Cabe ressaltar que o espaço, conforme Moreira (2014, p. 132), "é aqui concebido em sua relação processual com a sociedade no curso da qual o espaço cria a sociedade e a sociedade cria o espaço [...]". Isso nos mostra que fazer geografia e compreendê-la passa muito mais por pesquisar a/na realidade e agir com ela e sobre ela, do que ouvir informações soltas sobre determinadas características de determinada porção ou aspecto do território.

Kaercher (2000, p. 43) é categórico ao afirmar que "não tenho dúvida de que aquela geografia compartimentada em 'aspectos naturais, aspectos humanos e aspectos econômicos é um cadáver oferecido aos alunos", retratando um mundo que "só existe nos livros didáticos" (Id., 2000, p. 43). Este modelo de geografia compartimentada, tida como um conhecimento perfeito, ou seja, feito por completo, ao qual não cabem questionamentos não serve mais, sendo que já foi criticado por outros autores (MOREIRA, 2014).

Poderíamos fazer menção, a partir dos parâmetros didático metodológicos propostos ao longo do trabalho, de algumas temáticas a serem trabalhadas, tais como a realidade do aluno, ou seja, ao invés de utilizarmos exemplos distantes de sua realidade e trazer as informações prontas e mastigadas para este, poderíamos propor a temática central e convergir no sentido de identificar, analisar, sintetizar e avaliar como esta se relaciona ao seu cotidiano. No caso da hidrogeografia referido mais acima neste trabalho, poderíamos fazer a visita a 
algum rio da região, ver como este se comporta em relação à nascente, foz, margens, volume de água, conservação e preservação ao longo de suas margens, regime de cheias, enfim, visualizar os conceitos na prática e perceber como estes se relacionam como o ambiente e a sociedade do entorno.

Além disso, propomos que a partir destas informações coletadas, os discentes possam pensar e viabilizar ações práticas caso verifiquem algum problema, como desmatamento das margens, por exemplo. Assim, a escola conseguirá trabalhar os conteúdos não de forma tradicional e rígida, mas sim de acordo com os preceitos da metodologia do educar pela pesquisa, contribuindo ao desenvolvimento do aluno de um ponto de vista integral, não só cognitivo.

Finalmente, é importante que cada docente assuma a frente nesta seara, deixando de lados o corporativismo, a zona de conforto e não aguarde que outros façam a mudança em seu lugar, pois "o desenvolvimento da inteligência geral requer que seu exercício seja ligado à dúvida, fermento de toda atividade crítica [...]" (MORIN, 2003, p. 22), o que somente a educação pela pesquisa pode propiciar. Assim, é somente compreendendo que o modelo didático-metodológico de hoje não serve mais, que conseguiremos melhorar a qualidade da educação brasileira.

\section{CONSIDERAÇÕES FINAIS}

O aprendizado dos discentes na atualidade, especialmente os brasileiros, não tem sido muito satisfatório, isso em virtude do modelo de ensino defasado que insistimos em manter vivo. Os dados mostram que, enquanto nos anos finais do ensino fundamental ainda ocorre uma evolução, mesmo que de forma muito lenta, no ensino médio o cenário é praticamente de estagnação, melhor dizendo, a aprendizagem até "anda, porém, para trás" (DEMO, 2018, p. $13)$.

Tal cenário é propiciado pelo ambiente instrucionista que predomina na educação formal atual, formando alunos que não sabem pensar e não possuem autoria do seu conhecimento, fazendo com que estes pensem pela cabeça dos outros, isto é, não possuem capacidade de assunção de nenhum posicionamento ou opinião que seja sólido, já que não tem condições de fundamentar tal opção. Os dados do IDEB e do PISA confirmam este cenário.

Assim, juntamente com as outras disciplinas, a geografia escolar tem deixado bastante a desejar quando nos referimos a aprendizado, já que não vem conseguindo cumprir os seus 
objetivos. Isso ocorre devido ao modelo didático-metodológico que se utiliza e aplica na enorme carga horária de aulas e conteúdos a que os alunos são expostos diariamente. Cada vez mais, se dá aula e os conteúdos vistos aumentam cada vez mais, mas eles são somente vistos, já que, em grande parte das vezes, não são estudados e compreendidos.

Contudo, há algumas possibilidades de alterar esta conjuntura desalentadora por meio de mudanças paradigmáticas na concepção de aprendizagem dos docentes, bem como na alteração urgente do aspecto didático-metodológico, assumindo um posicionamento que possibilite a construção e reconstrução do conhecimento por parte dos discentes através de um modelo de educação pela pesquisa, onde se valoriza e se avalia não a capacidade de memória do aluno, mas sim sua autoria e sua evolução ao longo do processo educativo.

Em suma, há vários trabalhos e concepções que advogam que o discente deve ter um papel ativo no processo de aprendizado, que o professor deve ser um mediador neste processo, porém pouco se faz neste sentido. Os docentes por vezes não se preparam o suficiente para tal mudança, os alunos ficam inseguros e irrequietos, a conjuntura não colabora para tal e acaba-se retornando ao refúgio "seguro" das aulas de cunho instrucionista. Cabe a cada docente assumir o seu papel e tomar frente neste processo, pois somente a atitude propositiva e acertada, como a educação pela pesquisa, é que pode mudar os rumos da educação.

\section{REFERÊNCIAS}

AUGUSTO, T. G. da. S. et. al. Interdisciplinaridade: concepções de professores da área ciências da natureza em formação em serviço. Ciência \& Educação, v. 10, n. 2, p. 277-289, 2004. Disponível em: 〈http://www.scielo.br/pdf/ciedu/v10n2/09.pdf $>$. Acesso em: 2 jan. 2019.

BALISKI, P. Encaminhamentos metodológicos para o ensino de geografia. Curitiba: Intersaberes, 2016.

BOTH, I. J. Avaliação planejada, aprendizagem consentida: a fisiologia do conhecimento. Curitiba: IBPEX, 2007.

CASTELLAR, S. M. V. A psicologia genética e a aprendizagem no ensino de geografia. In: 38-50. Educação geográfica: teorias e práticas docentes. São Paulo: Contexto, 2005. p.

CAVALCANTE, M. Interdisciplinaridade: um avanço na educação. 2018. Disponível em: <http://novaescola.org.br/conteudo/249/interdisciplinaridade-um-avanco-na-educacao >. Acesso em: 2 jan. 2019. 
CAVALCANTI, L. de. S. Ensino de geografia e diversidade: construção de conhecimentos geográficos escolares e atribuição de significados pelos diversos sujeitos do processo de ensino. In: CASTELLAR, S. (Org.). Educação geográfica: teorias e práticas docentes. São Paulo: Contexto, 2005. p. 66-78.

DEMO, P. ABC: iniciação à competência reconstrutiva do professor básico. 4. ed. Curitiba: Ibpex, 2009.

DEMO, P. Adoro ensinar. 2015.Disponível em: $<$ https://docs.google.com/document/d/1TPKd6TfevuyvmUzF6dghnIq_58nN8mbGE7awlBgh o9E/pub>. Acesso em: 6 jan. 2019.

DEMO, P. (2018). Atividades de aprendizagem: sair da mania do ensino para comprometerse com a aprendizagem do estudante. 1st ed. [e-book] Campo Grande: Secretaria de Estado de Educação do Mato Grosso do Sul. Disponível em: <http://www.sed.ms.gov.br/wpcontent/uploads/sites/67/2018/12/eBook-Atividades-de-Aprendizagem-Pedro-Demo.pdf>. Acesso em: 6 jan. 2019.

DEMO, P. Professor do futuro e a reconstrução do conhecimento. Petrópolis: Vozes, 2004.

G1. Brasil cai em ranking mundial de educação em ciências, leitura e matemática. 2016. Disponível em: <https://g1.globo.com/educacao/noticia/brasil-cai-em-ranking-mundial-deeducacao-em-ciencias-leitura-e-matematica.ghtml>. Acesso em: 7 jan. 2019.

INEP - Instituto Nacional de Pesquisas Educacionais Anísio Teixeira. IDEB - Resultados e Metas. Disponível em: 〈http://ideb.inep.gov.br/resultado/>. Acesso em: 7 jan. 2019.

KAERCHER, N. A. A geografia serve para entender a água, o sangue, o petróleo... serve para entender o mundo, e, sobretudo, anos mesmos! In: FARIAS, P. S C.; OLIVEIRA, M. M. de. (Orgs.). A formação docente em geografia: teorias e práticas. Campina Grande: EDUFCG, 2014. p. 17-50.

KAERCHER, N. A. Geografizando o jornal e outros cotidianos: práticas em Geografia para além do livro didático. In: CASTROGIOVANNI, A. C. (Org.). Ensino de Geografia: práticas e textualizações no cotidiano. 11 ed. Porto Alegre: Mediação, 2014. p. 115-142.

KAERCHER, N. A. Práticas geográficas para lerpensar o mundo, converentendersar com o outro e enterdescobrir a si mesmo. In: REGO, N. et. al. (Org.). Geografia: práticas pedagógicas para o ensino médio. Porto Alegre: Artmed, 2007. p. 15-33.

KAERCHER, N. A. Sentado também se vai longe - A importância das cadeiras macias no ensino de geografia. Boletim Gaúcho de Geografia, Porto Alegre, v. 29, p. 39-52, jul., 2000. KRAUSZ, M. Onde as disciplinas se encontram. 2011. Disponível em: $<$ http://www.revistaeducacao.com.br/onde-as-disciplinas-se-encontram/>. Acesso em: 2 jan. 2019.

KRUSE, T.; PALHARES, I. Novo currículo do ensino médio será dividido em áreas, e não disciplinas. 2017.Disponível em: < http://educacao.estadao.com.br/noticias/geral,novo- 
curriculo-do-ensino-medio-sera-dividido-em-areas-e-nao-disciplinas,70001961759>. Acesso em: 2 jan. 2019.

LIRA, S. M. de. O ensino de geografia, a construção do conhecimento geográfico e a operacionalização da prática docente. In: FARIAS, P. S C.; OLIVEIRA, M. M. de. (Orgs.). A formação docente em geografia: teorias e práticas. Campina Grande: EDUFCG, 2014. p. 299-320.

MARTIN, O. B.; MOSER, A. Conceito de mediação em Vygotsky, Leontiev e Wertsch. Revista Intersaberes, Curitiba, v. 7, n. 13, p. 8-28, jan./jun. 2012.

MORAES, J. V. de. A teoria de Ausubel na aprendizagem do conceito de espaço geográfico. In: CASTELLAR, S. (Org.). Educação geográfica: teorias e práticas docentes. São Paulo: Contexto, 2005. p. 97-112.

MOREIRA, R. Para onde vai o pensamento geográfico: por uma epistemologia crítica. 2.ed. São Paulo: Contexto, 2014.

MORIN, E. A cabeça bem-feita: repensar a reforma, reformar o pensamento. 8.ed. Rio de Janeiro: Bertrand Brasil, 2003.

OLIVEIRA, G. M. P. de. et. al. O ato de estudar na vida acadêmica. Disponível em: $<$ http://www.prac.ufpb.br/anais/IXEnex/iniciacao/documentos/anais/4.EDUCACAO/4CFTD CSAMT01.pdf>. Acesso em: 6 jan. 2019.

PEREIRA, A. dos. S. Desafios contemporâneos para a geografia do Brasil. Curitiba: Intersaberes, 2016.

PEZZINI, C. C. Falta de desejo de aprender: causas e consequências. 2008. Orientação de outra natureza. (Programa de Desenvolvimento Educacional) - Universidade Estadual do Oeste do Paraná, Secretaria de Estado da Educação. Orientador: Maria Lidia Sica Szymanski. Disponível em: $\langle$ http://www.diaadiaeducacao.pr.gov.br/portals/pde/arquivos/853-2.pdf $>$. Acesso em: 6 jan. 2019. 